\title{
Экспериментальное определение уровней размерного квантования в структурах на основе квантовых ям твердых растворов $\mathrm{Cd}_{\mathrm{x}} \mathrm{Hg}_{1-\mathrm{x}} \mathrm{Te}$
}

\author{
В.Г. Ремесник ${ }^{1)}$, Н.Н. Михайлов ${ }^{1,2)}$, С.А. Дворецкий ${ }^{1,3)}$, И.Н. Ужаков ${ }^{1)}$ \\ ${ }^{1}$ Институт физики полупроводников им. А.В. Ржанова СО РАН, \\ Новосибирск, 630090, пр. Ак. Лаврентьева, 13 \\ ${ }^{2}$ Новосибирский государственный университет, 630090, Новосибирск, ул. Пирогова, 2 \\ ${ }^{3}$ Национальный исследовательский Томский государственный университет, \\ 634050, Томск, пр. Ленина, 36 \\ тел:+7 (383) 330-9923, факс: +7(383) 330-4967, эл. почта: remesnik@isp.nsc.ru
}

DOI 10.34077/RCSP2019-50

Перспективный материал на основе множественных квантовых ям (КЯ) твердых растворов $\mathrm{Cd}_{\mathrm{x}} \mathrm{Hg}_{1-\mathrm{x}} \mathrm{Te}$ может использоваться для создания как источников стимулированного излучения, так и фотоприемников, работающих в средневолновой и длинноволновой области ИК диапазона. Метод молекулярно-лучевой эпитаксии c in situ эллипсометрическим контролем позволяет воспроизводимо выращивать такие структуры. С использованием метода “эффективной” подложки можно восстановить профиль распределения состава в квантовых ямах. Однако определение уровней размерного квантования, которые определяют оптические и электрофизические свойства таких структур до сих пор остается не решенной задачей

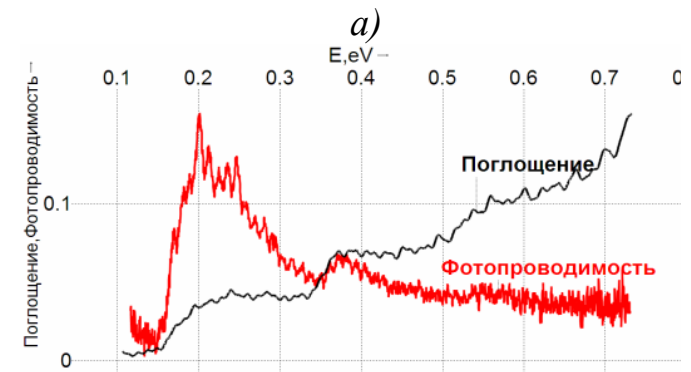

б)

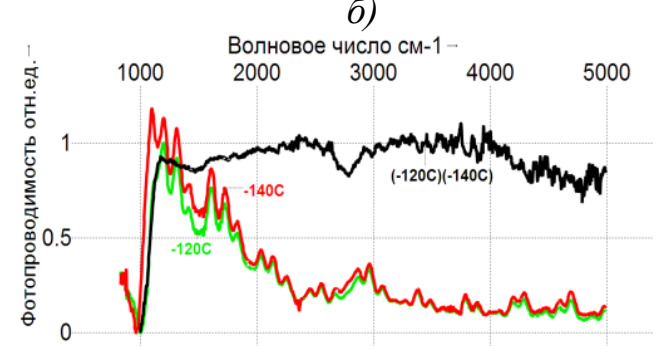

c)

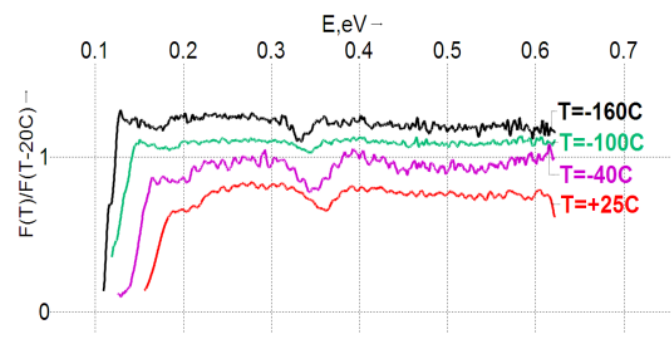

В работе предложены методики определения положения уровней размерного квантования в множественных КЯ, основанные на измерении спектров оптического поглощения $\mathrm{D}(\lambda)=\lg (1 /(\mathrm{T}+\mathrm{R}))$ и спектров продольной фотопроводимости $\mathrm{F}(\lambda)$ в диапазоне температур $\mathrm{T}=77 \div 298 \mathrm{~K}$.

В качестве примера на рис. 1а показано оптическое поглощение для структуры с 10 -ю КЯ с толщиной 9,4 нм $\left(\mathrm{X}_{\text {обкладки }}=0,65 \mathrm{X}_{\text {ям }} \cong 0,05\right)$. Видно, что с возрастанием энергии оптическая плотность имеет ступеньки, что определяется положением квантовых уровней, которые зависят от толщины КЯ. Аналогичная картина наблюдается и для спектров фотопроводимости.

На рис.1б показаны спектры $\mathrm{F}(\mathrm{T})$ при двух температурах и их отношение $\mathrm{F}(-120 \mathrm{C}) / \mathrm{F}(-140 \mathrm{C})$, позволяющее определять положение уровней без влияния интерференции. На рис.1с показано смещение этих уровней с температурой.

Приводятся зависимости энергетического положения уровней для широкого набора $\mathrm{HgTe}$ КЯ с толщинами от 2,7 до 11 нм при $\mathrm{T}=77 \mathrm{~K}$ и $\mathrm{T}=298 \mathrm{~K}$. Показано, что зависимость от толщины носит характер E 1/d. Так же представлены результаты для КЯ с мольным содержанием теллурида кадмия $\mathrm{X} \approx 0 \div 0.3$. Экпериментальные данные показывают, что положение уровней определяется как энергетическим барьером между ямами $\left(\mathrm{X}_{\text {обкладки }}\right)$ и толщиной ям $\mathrm{d}$, так

и мольным содержанием теллурида кадмия в ямах $\mathrm{x}_{\text {ямы }}$.

Работа выполнена при частичной финансовой поддержке РФФИ (проект №18-29-20053) и проекта №0306-2018-0010 